\title{
Pharmacokinetic interaction of ketoconazole, clarithromycin, and midazolam with riociguat
}

\author{
Corina Becker ${ }^{1 * \dagger}$, Reiner Frey ${ }^{1}$, Sigrun Unger ${ }^{2}$, Dirk Thomas ${ }^{1}$, Michael Reber ${ }^{1}$, Gerrit Weimann ${ }^{1}$, Hartmut Dietrich ${ }^{3}$, \\ Erich R Arens ${ }^{1}$, Wolfgang Mueck ${ }^{1}$
}

From 6th International Conference on cGMP: Generators, Effectors and Therapeutic Implications

Erfurt, Germany. 28-30 June 2013

\section{Background}

Riociguat, an oral soluble guanylate cyclase stimulator, is under investigation for pulmonary hypertension treatment. Cytochrome P450 (CYP)-mediated oxidative metabolism is one of the major riociguat clearance pathways.
The pharmacokinetic interactions between riociguat and ketoconazole (multi-pathway CYP and P-glycoprotein/ breast cancer resistance protein $[\mathrm{P}$-gp/BCRP] inhibitor), clarithromycin (CYP3A4 inhibitor), and midazolam (CYP3A4 substrate) were investigated.

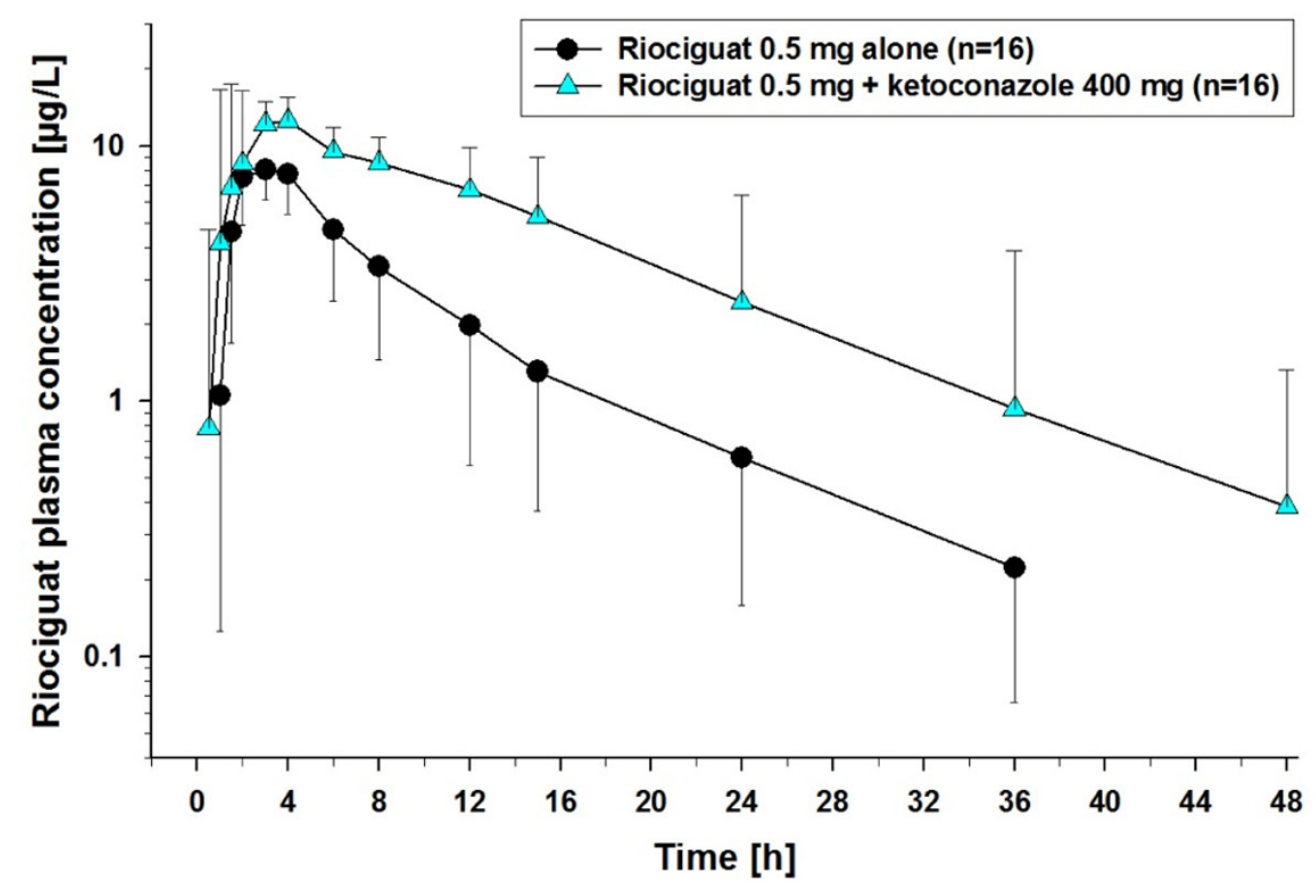

Figure 1 Plasma concentrations of riociguat $0.5 \mathrm{mg}$ alone or in combination with ketoconazole $400 \mathrm{mg}$.

\footnotetext{
* Correspondence: corina.becker@bayer.com

† Contributed equally

'Clinical Pharmacology, Bayer HealthCare Pharmaceuticals, Wuppertal,

Germany

Full list of author information is available at the end of the article
}

(c) 2013 Becker et al; licensee BioMed Central Ltd. This is an Open Access article distributed under the terms of the Creative Commons 


\section{Methods}

Three open-label, randomized, crossover studies were performed in healthy males. In the first study, subjects received riociguat $0.5 \mathrm{mg} \pm$ ketoconazole (4-day pretreatment with once-daily [od] ketoconazole $400 \mathrm{mg}$, then riociguat +1 dose of ketoconazole $400 \mathrm{mg})(\mathrm{n}=16)$. In the second study, subjects received riociguat $1 \mathrm{mg} \pm$ clarithromycin (4-day pretreatment with twice-daily clarithromycin $500 \mathrm{mg}$, then riociguat +1 dose of clarithromycin $500 \mathrm{mg})(\mathrm{n}=14)$. In the third study, subjects received three-times daily (tid) riociguat $2.5 \mathrm{mg}$ for 3 days, then 1 day of riociguat $2.5 \mathrm{mg}$ tid \pm midazolam $7.5 \mathrm{mg}(\mathrm{n}=24)$. Pharmacokinetic parameters, safety, and tolerability were assessed.

\section{Results}

Pre- and co-treatment with ketoconazole increased riociguat mean AUC by $150 \%$ and mean $C_{\max }$ by $46 \%$ (Figure 1;

Table 1 The effects of ketoconazole and clarithromycin on riociguat pharmacokinetics (geometric means and coefficients of variation)

\begin{tabular}{|c|c|c|c|c|c|c|c|c|}
\hline \multirow{3}{*}{ Parameter } & \multicolumn{4}{|c|}{ Riociguat/ketoconazole study } & \multicolumn{4}{|c|}{ Riociguat/clarithromycin study } \\
\hline & \multicolumn{2}{|c|}{ Riociguat $0.5 \mathrm{mg}(\mathrm{n}=16)$} & \multicolumn{2}{|c|}{ Riociguat $0.5 \mathrm{mg}+$ ketoconazole $(\mathrm{n}=16)$} & \multicolumn{2}{|c|}{ Riociguat $1 \mathrm{mg}(\mathrm{n}=14)$} & \multicolumn{2}{|c|}{ Riociguat $1 \mathrm{mg}+$ clarithromycin $(\mathrm{n}=14$} \\
\hline & GM & $\% C V$ & GM & $\% C V$ & GM & $\% C V$ & GM & $\% C V$ \\
\hline$A \cup C(\mu g \cdot h / L)$ & 81.9 & 78.6 & 204.9 & 44.9 & 171.1 & 97.0 & 240.0 & 88.9 \\
\hline$C_{\max }(\mu g / L)$ & 9.4 & 29.9 & 13.7 & 19.3 & 20.8 & 37.7 & 21.6 & 33.9 \\
\hline$t_{1 / 2}(h)$ & 7.3 & 78.5 & 9.2 & 57.1 & 6.4 & 77.1 & 7.9 & 54.6 \\
\hline$C L / f(L / h)$ & 6.1 & 78.6 & 2.4 & 44.9 & 5.8 & 97.0 & 4.2 & 88.9 \\
\hline
\end{tabular}

$\mathrm{AUC}$, area under plasma concentration-time curve; $\mathrm{CL} / \mathrm{f}$, total riociguat clearance from plasma; $\mathrm{C}_{\max }$ maximum riociguat plasma concentration; $\mathrm{CV}$, coefficient of variation; $\mathrm{GM}$, geometric mean; $\mathrm{t}_{1 / 2}$, elimination half-life.

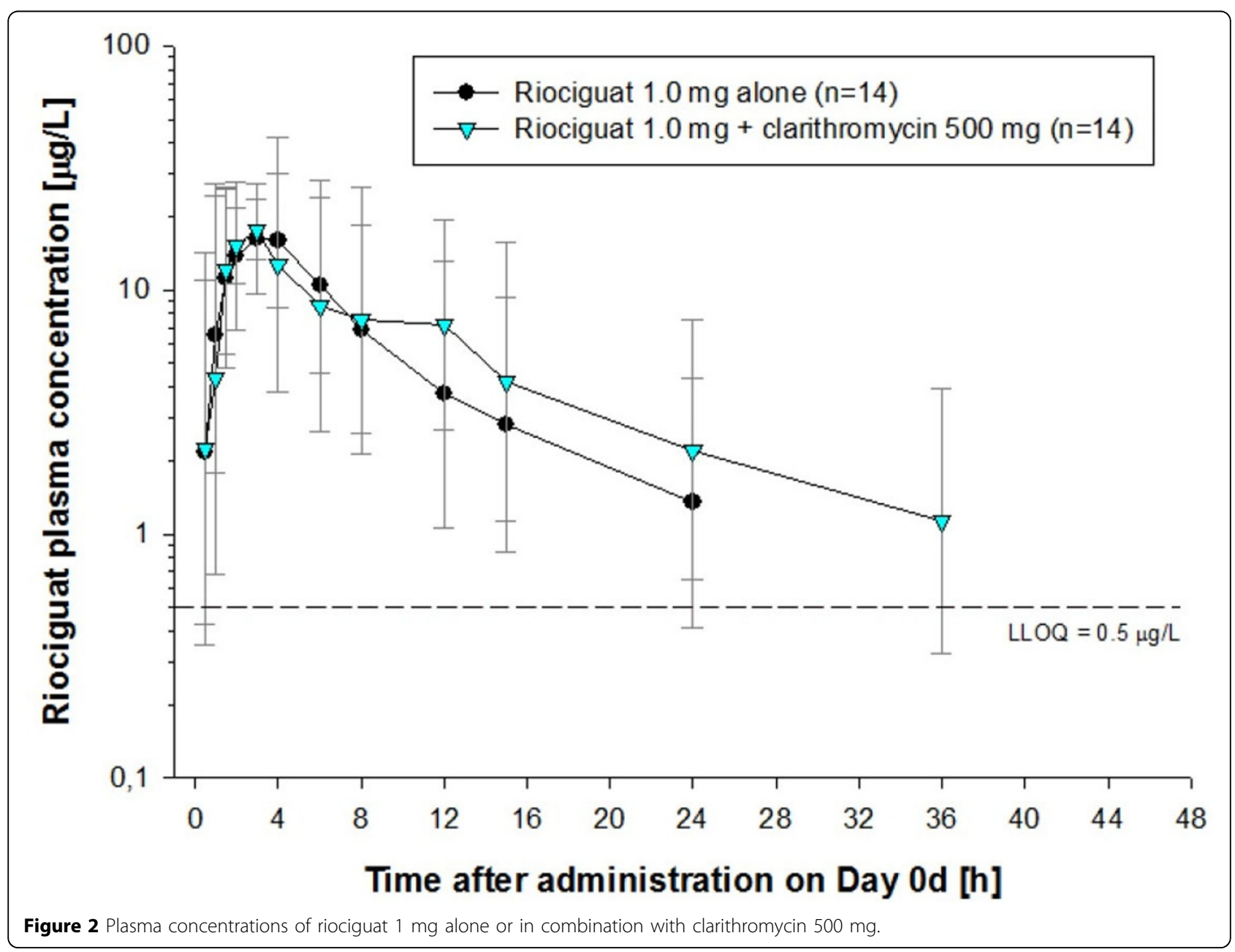


Table 1). Pre- and co-treatment with clarithromycin increased riociguat AUC by $41 \%$ without significantly increasing $\mathrm{C}_{\max }$ (Figure 2; Table 1). Riociguat pre- and cotreatment did not significantly alter the AUC or $\mathrm{C}_{\max }$ of midazolam (Figure 3; Table 2). In the ketoconazole study, adverse events (AEs) were reported in 4 (25\%), 6 (38\%), and $5(31 \%)$ subjects treated with riociguat alone, riociguat + ketoconazole, and ketoconazole alone, respectively. In the clarithromycin study, AEs were reported in $4(29 \%), 9$ (64\%), and 9 (64\%) subjects treated with riociguat alone, riociguat + clarithromycin, and clarithromycin alone, respectively. In the midazolam study, AEs were reported in
$20(87 \%), 11(48 \%)$, and $6(27 \%)$ subjects treated with riociguat alone, riociguat + midazolam, and midazolam alone, respectively. The most common AEs with riociguat \pm ketoconazole, clarithromycin, and midazolam across the three studies were headache and dyspepsia. One serious $\mathrm{AE}$ was reported in the midazolam study (elevated creatine phosphokinase; not drug-related).

\section{Conclusions}

The combined use of riociguat with multi-pathway inhibitors such as anti-mycotics (eg ketoconazole) or HIV protease inhibitors should be avoided due to the

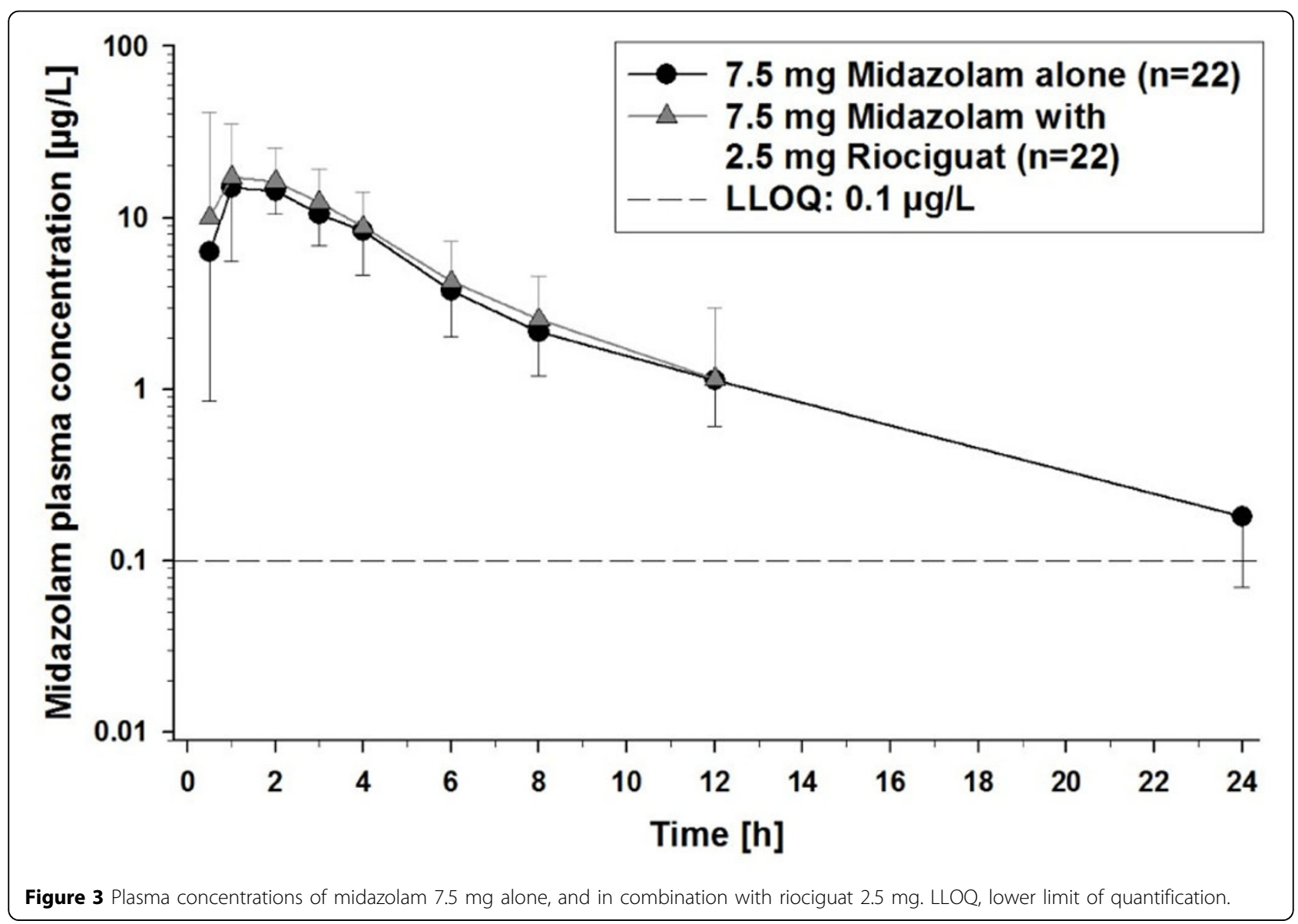

Table 2 The effects of riociguat on midazolam pharmacokinetics (geometric means and coefficients of variation)

\begin{tabular}{lcccc}
\hline \multicolumn{4}{c}{ Midazolam/riociguat study } \\
\hline Parameter & \multicolumn{2}{c}{ Midazolam $(\mathrm{n}=22)$} & \multicolumn{2}{c}{ Midazolam + riociguat 2.5 mg $(\mathrm{n}=22)$} \\
\hline $\mathrm{AUC}(\mu \mathrm{g} \cdot \mathrm{h} / \mathrm{L})$ & $\mathrm{GM}$ & \%CV & $\mathrm{GM}$ & \%CV \\
$\mathrm{C}_{\max }(\mu \mathrm{g} / \mathrm{L})$ & 91.1 & 34.3 & 98.2 & 37.0 \\
$\mathrm{t}_{1 / 2}(\mathrm{~h})$ & 29.0 & 45.1 & 29.5 & 41.5 \\
\hline
\end{tabular}

AUC, area under plasma concentration-time curve; $C_{\max }$ maximum riociguat plasma concentration; $C V$, coefficient of variation; $G M$, geometric mean; $t_{1 / 2}$, elimination half-life. 
expected increase in riociguat exposure. General dose adaptation for patients with co-medication inhibiting the CYP3A4 pathway or the P-gp/BCRP-mediated excretion of riociguat, beyond the dose titration concept for riociguat, is not deemed necessary. Riociguat \pm ketoconazole, clarithromycin, or midazolam was generally well tolerated.

\section{Acknowledgements}

The studies were funded by Bayer HealthCare Pharmaceuticals, Wuppertal, Germany. Medical writing assistance was provided by Adelphi

Communications Ltd, Bollington, UK and funded by Bayer HealthCare

Pharmaceuticals.

\section{Authors' details}

'Clinical Pharmacology, Bayer HealthCare Pharmaceuticals, Wuppertal,

Germany. ${ }^{2}$ Global Biostatistics, Bayer HealthCare Pharmaceuticals, Wuppertal, Germany. ${ }^{3} \mathrm{ClinPharmCologne,} \mathrm{MEDA} \mathrm{Manufacturing} \mathrm{GmbH,} \mathrm{Cologne,}$

Germany.

Published: 29 August 2013

\section{doi:10.1186/2050-6511-14-S1-P5}

Cite this article as: Becker et al:: Pharmacokinetic interaction of

ketoconazole, clarithromycin, and midazolam with riociguat. $B M C$

Pharmacology and Toxicology 2013 14(Suppl 1):P5.

\section{Submit your next manuscript to BioMed Central} and take full advantage of:

- Convenient online submission

- Thorough peer review

- No space constraints or color figure charges

- Immediate publication on acceptance

- Inclusion in PubMed, CAS, Scopus and Google Scholar

- Research which is freely available for redistribution

Submit your manuscript at www.biomedcentral.com/submit 